\title{
O PAPEL DO EMPREENDEDORISMO NA URBANIZAÇÃO E INDUSTRIALIZAÇÃO DA CIDADE DE SÃO PAULO: A FORMAÇÃO DA MALHA FERROVIÁRIA DO INTERIOR PAULISTA
}

\author{
ENTREPRENEURSHIP'S ROLE IN THE DEVELOPMENT \\ AND INDUSTRIALIZATION OF THE CITY OF SÃO PAULO: \\ The LOOP FORMING OF RAILWAY INTERIOR PAULISTA
}

Recebido: 03/02/2016 - Aprovado: 23/10/2016 - Publicado: 29/04/2016 Processo de Avaliação: Double Blind Review

\author{
Palmira Petratti Teixeira \\ Dr $^{\mathrm{a}}$ em História - USP, Professora da UNESP. ${ }^{1}$ \\ palmirapetratti@uol.com.br
}

\section{Thais Cristina Pereira}

Especialista em História, Sociedade e Política - PUCSP

palmirapetratti@uol.com.br

\begin{abstract}
RESUMO: O estudo da “The São Paulo Railway Limited (SPR)" se torna tema instigante quando relacionado às transformações econômicas e sociais que ocorreram a partir da segunda metade do século XIX. Ao binômio café-ferrovia, acrescentamos a urbanização e a industrialização, passando pela Abolição e o advento da República. A estrada de ferro Santos a Jundiaí ou "A Inglesa" ou a São Paulo Railway (SPR), retrato da consolidação do capitalismo em São Paulo e responsável, em grande parte, pela mudança do cenário urbano desta cidade.
\end{abstract}

Palavras-Chave: Ferrovia; Urbanização; Industrialização; Empreendedores.

\footnotetext{
1 Autor para correspondência: Universidade de São Paulo: Departamento de História e Geografia. Av. Prof. Lineu Prestes, 338 - Butantã, São Paulo - SP, Brasil, 05508-000.
} 
ABSTRACT: To study the São Paulo Railway company's history becomes a very interesting theme, related to the economic and social changes which ocurred in São Paulo state since the 19 th centrury. To the coffee-railwaly bynomiun, one can add the urbanization and industrialization processes, the end slaverism and the republic's born too. This railroad, called also as "Santos a Jundiai Railway" or "A inglesa" (The English), expressed the consolidation of capitalism in S. Paulo state, due to dramatic changes that its construction determined in the S. Paulo city urban aspects.

Keywords: Railroad; urbanization; industrialization; entrepreneurs.

\section{INTRODUÇÃO}

Escrever sobre ferrovias é sempre uma atividade prazerosa. Nela encontramos, além de mudanças socioeconômicas e urbanistas, a presença dos empreendedores que sonharam com o progresso e apostaram em seus sonhos.

Tocamos em pontos referenciais da memória coletiva. O trem, as estações, com os seus sons e aromas, são comuns a muitos de nós, oriundos ou não do interior paulista, que temos no trem a visão romântica ou saudosista de um universo que deixamos para trás.

Nossa análise tem como cerne as teorias do economista Joseph Alois Schumpter, segundo o qual as crises capitalistas poderiam ser mais rapidamente superadas graças às inovações de empresários capazes de mobilizar o capital, transformando ideias em novos métodos produtivos ou sistemas organizacionais.

Schumpter afirma que esses novos empreendedores são "espíritos livres", em condições de criar inovações tecnológicas e financeiras para vencer a concorrência e ser bemsucedidos em épocas de baixos rendimentos. Esses indivíduos teriam a responsabilidade pelo inesgotável aprimoramento do capitalismo, à medida que seriam os únicos a superar os impasses estruturais da iniciativa privada (SCHUMPTER, 1961).

Inspirados nessa noção do economista, podemos interpretar a importância de algumas trajetórias na conformação da metrópole paulistana ao desvendar a sutil combinação entre os interesses de classe, a consciência do papel político e econômico da elite paulista e a capacidade de realização e empreendimento. Assim, tais indivíduos tornam-se, ao mesmo 
tempo, expressão objetiva de certas tendências históricas e a manifestação subjetiva da criatividade humana.

Devemos salientar a íntima relação dos empreendedores com o poder, numa mescla de eficiência, mérito pessoal, patrimonialismo e jogo político. Eles atuaram na esfera pública, ocuparam cargos políticos e foram, destacadamente, grandes técnicos, engenheiros, urbanistas, planejadores. Receberam, em troca, o prestígio de que necessitavam para o crescimento de suas atividades. (TEIXEIRA-PETRATTI, 2004, p.331)

O crescimento acelerado do café e a introdução da modernização capitalista no Brasil, com as inovações tecnológicas, oferecem oportunidades ao empreendedor de promover novas atividades de produção e prestação de serviços.

No epicentro das crises, mulheres e homens se destacam por sua insistência em sonhar, ousar, arriscar, realizar. São pessoas que revelam habilidades para enfrentar desafios com sucesso ou retirar dos fracassos lições que inspiram a continuação exitosa de sua caminhada. (MARCOVITCH, 2003, p.20)

A chegada das ferrovias, que desenhavam os caminhos de ferro do estado de São Paulo, introduziu mudanças e hábitos e interferiu diretamente nas economias locais. O tempo, marcado pelo soar dos sinos das igrejas, era agora controlado pelo apito do trem. Estações e atividades a elas ligadas, a chegada do correio, dos jornais e das revistas de modas, "as partidas e chegadas" e o caminho do trem, cortando o meio rural, trouxeram novos agentes sociais da história e incorporaram seus valores às cidades nascidas de pequenas estações, historizando novas imagens e representações (TEIXEIRA-PETRATTI, 2010).

\section{CAFÉ, FERROVIA, URBANIZAÇÃO E INDUSTRIALIZAÇÃO}

O café foi introduzido em São Paulo pelas vias fluminenses do litoral e do planalto, iniciando a quebra do domínio da exportação de cana-de-açúcar na segunda metade do século XIX e, em 1854, já se observava o aumento das fazendas de café, superando a supremacia do açúcar (Teixeira-Petratti, 2000).

Ao binômio café-ferrovia propulsor de atividades econômicas devem ser acrescentados os fenômenos da urbanização e da industrialização, ou seja, a atividade cafeeira e o advento do trem. Especialmente a este último podemos atribuir grande peso na 
consolidação do sistema capitalista em São Paulo, como fator responsável pelas mudanças do cenário espacial e social dessa cidade.

Essa foi uma época significativa, pois passaria a São Paulo a primazia da expansão cafeeira. E, ao final do Império, com a vinda da imigração europeia, ocorreu um reflexo direto no aumento das culturas, inaugurando-se uma nova era para a força de trabalho que durante todo o período colonial e imperial se sustentara no braço escravo.

Embora o grosso da imigração tenha se constituído do italiano que se dirigia para a agricultura ou pequenas propriedades, não devemos deixar de mencionar a presença do imigrante alemão, suíço e português, colaborando para o aumento da área cafeeira cultivada.

O café cultivado em áreas rurais transforma-se em atividade urbana no momento de sua negociação para a exportação. O sistema precário das estradas de rodagem, especialmente a de difícil ligação São Paulo / Santos, e a presença da tropa de muares representavam obstáculos severos à expansão cafeeira rumo ao Oeste paulista.

O desenvolvimento da agricultura cafeeira em torno de Campinas e mesmo além coloca uma dupla dificuldade: era preciso vencer mais de $200 \mathrm{~km}$ em tropas de mulas e era preciso que o porto de Santos fosse equipado pela a manutenção de uma tonelagem crescente. Um viajante alemão, Tschudi, notou em 1860, que era impossível plantar além de Rio Claro, pois a distância a vencer era muito grande. Alguns anos antes em 1855, o governador do Estado calculou em 500.000 arrobas de gêneros exportáveis permaneciam no lugar de produção por causa do custo alto do transporte (MONBEING, 1952, p. 86).

A partir de 1870 é retomada com vigor a questão da mão-de-obra. A política de incentivo à imigração é emblemática. Fazendeiros empenhavam-se em apresentar soluções para os problemas do transporte. A "modernização" chegara (GRAHAN, 1973, p.37).

Por volta de 1860-1880 vinculou-se a expansão cafeeira ao advento ferroviário. Surgiram as primeiras ferrovias dando início ao predomínio de uma nova mentalidade, dirigida pelos interesses da cafeicultura, que fizeram de seus interesses, interesses do Estado: "Os interesses de mão de obra e consequentemente os do povoamento, das vias de comunicação, os dos preços foram considerados e tratados antes de tudo em função dos interesses de fazendeiros: a marcha pioneira foi antes de mais nada o seu negócio." (MONBEIG, op. cit., p.1924)

Paralelos ao advento dessa cultura, outros fenômenos revelaram o aumento da população: o advento do trabalho livre e o desenvolvimento de centros urbanos. Do ponto de 
vista social e político destacou-se a ascensão dos fazendeiros, grandes proprietários de terra de café, englobando em torno de si a gerência da vida regional e nacional.

Muitos deles tornaram-se, durante a Primeira República, os "homens de estado" de fato e, muitas vezes de direito, apoiados que eram em suas fortunas provenientes do café, as mesmas que acabariam em parte suscitando o surto industrial moderno e provocando a liderança político-econômica paulista. A mudança do cenário urbano da cidade de São Paulo foi pré-requisito para o estabelecimento industrial (TEIXEIRA-PETRATTI, 2000, p. 24).

Foi nos centros urbanos que as sociedades instituídas de acionistas se originaram. "Aqui surgem os setores de serviços urbanos (transportes, bondes, iluminação, água e energia) como os mais evidentes. Ao mesmo tempo, vale observar o desenvolvimento do comércio e dos bancos no período" (SAES, 1979, p. 183).

A expansão da cultura cafeeira incrementou a atividade comercial. As casas comissárias, próximas ao porto de Santos, geralmente de propriedade de estrangeiros, compravam o café do produtor para exportá-lo. Havia um entrelaçamento de interesses entre produtor de café, ferrovias e comércio exportador.

A essa rede de interesses juntou-se a atividade financeira. Os empréstimos concedidos aos fazendeiros quando o café ainda estava no pé, descontados na ocasião da entrega do produto, atraíram bancos estrangeiros a investir em agências na praça de Santos ou de São Paulo.

A "The São Paulo Railway" (SPR) ou "A Inglesa" inaugurou a construção ferroviária no Estado de São Paulo, ligando Santos à Capital em 1865. Atingiu Jundiaí em 1868. Idealizada pelo Barão de Mauá, passou para as mãos dos ingleses em negociação que desagradou a seu idealizador Mauá.

O futuro Barão e Visconde de Maná, Irineu Evangelista de Souza, nasceu em 1813 no Rio de Grande do Sul. Órfão de pai, aos nove anos de idade (1822) começou a trabalhar como caixeiro de uma loja comercial no Rio de Janeiro. Viveu até outubro de 1889.

Nessa casa comercial, o inglês Richard Carruthers faria do estudioso caixeiro seu protegido, depois seu amigo, sócio e por fim compadre. Aprendeu inglês o tornou-se conhecedor dos segredos comerciais.

$\mathrm{Na}$ Inglaterra (1840) recebeu forte influência da Revolução Industrial que ali se processava: o vapor, o carvão, a locomotiva, os jornais em massa e as cidades iluminadas. 
Os empreendimentos de Mauá refletiam as profundas transformações por que passou a economia brasileira ao longo do Império, porém, muitas vezes sua atuação assumiu proporções tamanhas que influenciou a evolução dos próprios acontecimentos. Assim, Mauá tem duplo papel na história do Brasil. Primeiro, como empresário inserido no processo de transformações de sua época e segundo, Mauá, o agente de importantes transformações que, estava bem além da visão da maior parte de seus pares (SAES, 1987, p. 81-105).

O que nos importa é o significado de suas ações na sua época. Abstemo-nos dos fatos que comprometeram seus sucedidos negócios e o levaram à falência em 1875.

Mauá, riquíssimo aos trinta anos de idade se sentia atraído pela indústria. Conseguiu lançar as bases da mesma num período protecionista. Sofreu o efeito desastroso da retirada desta proteção e jamais se conformou com o fato do governo ter favorecido o café em detrimento da indústria (DI CROPANI, 1987, p. 23-39). Era um empresário liberal e abolicionista. Não valorizava os títulos nobiliários que recebera.

Os produtos gerados pela técnica da Revolução Industrial, identificados mais em setores urbanos que propriamente industriais, começaram a ser introduzidos no Brasil a partir de 1858 , constituindo o processo chamado de modernização (limitada a setores urbanos), uma vez que esta foi bloqueada pela presença do trabalho escravo.

Mauá imaginou um modelo de desenvolvimento baseado na industrialização, onde a indústria pesada seria o eixo propulsor deste processo. Seus empreendimentos devem ser vistos como elementos do processo de constituição desse modelo e não simplesmente como investimentos realizados em função de oportunidade de momento. Representante do capital mercantil nacional deu passos no sentido industrial. As palavras de Mauá atestam: "Causoume forte impressão o que vi e observei, e logo aí se gerou em meu espírito a ideia de fundar em meu país um estabelecimento a que me refiro" (MAUÁ, 1878).

Após as primeiras investidas de Mauá na indústria ferroviária, assistimos na década de 1870 uma onda de construção de linhas e ramais especialmente na região cafeeira.

Sendo a São Paulo Railway a única linha paulista a atingir o Porto de Santos e depois a cidade de Jundiaí, próxima à grande região produtora, toda a produção cafeeira utilizava o seu transporte, motivo pelo qual a empresa não se interessou em ampliar sua malha ferroviária para chegar até Campinas. O sucesso econômico da Santos Jundiaí foi fator decisivo para o investimento ferroviário. A ela seguiram-se inúmeras companhias nacionais, formadas por 
capital nacional originário da atividade rural ou do comércio, provocando um impacto na urbanização não só da capital provincial, mas também das cidades por onde passavam as ferrovias.

Diante do desinteresse da Inglesa em prolongar suas linhas, o presidente da província, Saldanha Marinho, iniciou os entendimentos para o prolongamento da linha Jundiaí-Campinas com a subscrição de acionistas. Fundou-se a Companhia Paulista de Estradas de Ferro, com capital exclusivamente nacional. Esta foi constituída como sociedade anônima, em que alguns grupos tinham presença destacada: Silva Prado, Souza Queiroz, Vergueiro e Paes de Barros. A origem de seu capital estava ligada à cafeicultura, intermediária entre produtores e exportadores.

Os acionistas da Paulista procuraram servir regiões já valorizadas, não estabelecendo suas linhas senão em territórios já povoados. Muitos fazendeiros incorporadores da estrada tinham seus interesses em áreas situadas além de Campinas e jamais se conformariam que a Paulista se detivesse naquela região. Os trabalhos de construção tiveram início em 19 de janeiro de 1874, inaugurando-se os trechos de Santa Bárbara, Limeira, Rio Claro, Cordeiro (atual Cordeirópolis), Leme, Araras, Porto Ferreira e Descalvado até 1881. Três companhias são organizadas, com pequeno intervalo, não só no sentido de levar os trilhos de Campinas a outras regiões, mas também de procurar a ligação de outras regiões diretamente à capital, sem a utilização do tronco inicial da Paulista ou da linha São Paulo-Jundiaí. É o caso, por exemplo, da Ituana, da Sorocabana e da Mogiana (MATOS, 1974, p. 63).

A família Silva Prado, Antônio Queiroz Teles e José Estanislau do Amaral (grandes proprietários de café) e o Barão do Tietê (presidente da empresa de Seguros Cia. União Paulista) estavam entre os principais acionistas da Mogiana (1872). A Ituana (1873) era controlada pelas famílias de cafeicultores Paes de Barros (Cia. Paulista) e Pacheco Jordão.

O ano de 1872 assistiu à fundação da Mogiana, em Campinas. Assim como nas demais, seus incorporadores eram homens ligados ao café. Essa ferrovia serviria uma das mais ricas regiões da então província de São Paulo, atingindo mais para o fim do século as divisas com Minas Gerais e penetrando em território mineiro, onde se articulou com outras ferrovias. A Mogiana teria o papel de capturar para a economia paulista grande parte do sul de Minas e do chamado Triângulo Mineiro. A Mogiana realizou a ligação entre a região de Campinas e Araguari (ibidem, p. 68). 
Nem havia ainda a Paulista inaugurado seu primeiro trecho até Campinas quando abonados fazendeiros da região Ituana resolveram incorporar uma companhia destinada a estabelecer a ligação ferroviária de sua cidade com Jundiaí (ibidem, p. 66). A empresa Sorocabana (1875), embora, da mesma época, teve uma característica distinta. A elevação dos preços do algodão no mercado internacional durante a Guerra de Secessão norte-americana estimulou a plantação desse produto em São Paulo. A Sorocabana nasceu da necessidade da redução dos custos de transportes dos proprietários de terra ligados a essa cultura (SAES, 1974, p.59-70). O grande mérito de tal ferrovia foi de levar seus trilhos até as margens do Paraná, no meio de uma região ainda virgem e despovoada.

À medida que a linha progride para o interior, fez nascer em sua extremidade cidades que se povoam com espantosa rapidez. Essas cidades de vanguarda são "as bocas do sertão", "as portas da mata". O caminho de ferro tem assim merecido o belo epiteto de "plantador das cidades". (OLIVEIRA, 2003, p. 52).

Posteriormente, temos a formação da Companhia Estrada de Ferro Noroeste do Brasil (1905), na cidade de Bauru, considerada "boca do sertão". A ferrovia representou o acesso a áreas inatingíveis e uma indiscutível destruição dos gentios, em uma clara união de interesses dos desejosos de apropriar-se das terras devolutas e dos que almejavam avançar com os trilhos da estrada. No Noroeste, a ferrovia precede à lavoura, abrindo caminho para ela.

A estrada de ferro Araraquarense (1901) atingiu as férteis terras da cidade de São José do Rio Preto em 1912.

As estradas de ferro transformaram vilas em cidades progressistas e a marcha para o oeste contribuiu para englobar novas áreas de cultivo.

A cidade de São Paulo passou a ser o lugar de residência dos "barões do café", acelerando a expansão das atividades urbanas e de serviço de utilidade pública. Isso nos mostra a íntima relação entre atividades urbanas, fazendeiras e ferrovias. A inauguração do Teatro Municipal de São Paulo em 1911 é a expressão máxima da ascensão politica e social dos cafeicultores.

A atividade ferroviária, como já afirmamos, teve impacto no processo de urbanização e no aparecimento de novas cidades ligadas às estações ferroviárias, sedes e oficinas. 
Existe uma relação direta entre as estradas de ferro e as grandes aglomerações urbanas. A experiência tem demonstrado que aquelas são um extraordinário instrumento de penetração, um importante fator de povoamento, influenciando o crescimento da população das regiões por onde passam. (AZEVEDO, 1950, p. 29)

Foi também fator decisivo pouco mais tarde, quando da industrialização e da formação de bairros e vilas operárias. O industrial, ao escolher um terreno para instalação de sua indústria, levava em conta a proximidade com a estação ou ramal ferroviário, também fator relevante para a capital e as atividades econômicas do interior do Estado.

Entre 1900 e 1907, com relação ao crescimento industrial na capital, observamos que o número de estabelecimentos cresceu $126 \%$ enquanto o número de operários aumentou 91\%, o que tornava imperiosa a fixação da mão de obra. Assim, o processo de urbanização, iniciando a partir dos anos 70 do século XIX, foi extremamente rápido, impulsionado pela atividade cafeeira e pelo começo da atividade industrial. No fim da década de 1890, já se desenhava a configuração urbana espaço--social que foi acentuada e definida nas primeiras décadas do século XX: na parte alta, no maciço, os bairros mais ricos, e na parte baixa, ao longo dos rios Tietê e Tamanduateí, na várzea, os bairros e as vilas operárias. (TEIXEIRA- PETRATTI, 1990, p. 70-4).

\section{CONSIDERAÇÕES FINAIS}

Para compreender as transformações ocorridas com a implantação da ferrovia é necessário considerar a conjugação de rural e urbano, de agrícola e industrial, de antigo e novo. O mundo moderno impôs modificações à vida cotidiana, demarcada pela nova temporalidade, de horários estritos, disciplinados e contados em seus ínfimos segundos; e pela nova paisagem, ampla, diversificada e longínqua. Porém, as transformações foram inserindose lentamente nos interstícios dos costumes e repetições, inaugurando novas mentalidades no século que se iniciava.

A introdução das ferrovias na cidade de São Paulo está intimamente ligada à urbanização decorrente das riquezas da exploração cafeeira e ambas foram pré-requisitos para a instalação da atividade industrial. Havia capital e mão de obra para impulsionar novos empreendimentos. Mas, sobretudo, houve homens corajosos e audaciosos empreendedores que, com suas ações, transformaram o rumo da história desta cidade e Mauá talvez tenha sido um dos maiores empreendedores nacionais. 


\section{REFERÊNCIAS}

ANDRADE e SILVA, Raul; MATOS, Odilon Nogueira de; PASQUALE, Petrone. Evolução urbana de São Paulo. In. Revista de História, São Paulo, 1955, pp. 53 e seguintes.

DI COMPRANI, Ottaviano de Fiori. Mauá e a Industrialização Brasileira. In. Barão de Mauá: Empresário e Politico. São Paulo: Bianchi Editores, 1987.

GRAHAN, Richard. Grã-Bretanha e o início da industrialização no Brasil 1850-1940. São Paulo: Brasiliense, 1973. Rio de Janeiro: Ed. Paz e Terra, 1990.

MARCOVITCH, Jacques. Pioneiros e Empreendedores: A saga do desenvolvimento no Brasil. São Paulo: EDUSP, 2003.

MAUÁ. Exposição do Visconde de Mauá aos credores de Mauá e Cia. Rio de Janeiro, Typ. Imp. e Const. de J. Villeneuve \& Cia., 1878.

MONBEIG, Pierre. Pionniers et plateurs de São Paulo. Paris: Librarie Armand Collin, 1952.

SAES, Flávio A. M. A Grande empresa de serviços públicos na economia cafeeira. Tese de doutoramento, USP, São Paulo, 1979.

SAES, Flávio A. M. As ferrovias de São Paulo 1870-1940: expansão e declínio ferroviário em São Paulo. São Paulo: HUCITEC, 1981.

SAES, Flávio A. M. Café, população e ferrovias em São Paulo: o estabelecimento de diretrizes das estradas de ferro. São Paulo, HUCITEC, INL, 1981.

SCHORER, Petrone. Imigração assalariada. In. HOLANDA, Sergio Buarque. História geral da civilização Brasileira, tomo II, volume 3. São Paulo: Difusão Europeia do Livro, 1976.

SCHUMPETER, Joseph Alois. Teoria do Desenvolvimento econômico. Rio de Janeiro: Fundo de Cultura, 1961.

TEIXEIRA, Palmira Petratti. A Fábrica do Sonho: trajetória do industrial Jorge Street. Rio de Janeiro: Paz e Terra, 1990.

TEIXEIRA, Palmira Petratti. A institucionalização da São Paulo Railway. São Paulo: Kid's Produções Gráficas, 2000.

TEIXEIRA, Palmira Petratti. Empreendedores na cidade de São Paulo: Dos primórdios aos grandes empresários. In. PORTA, Paula (org.).História da cidade de São Paulo: A cidade colonial 1554-1822. v. I. São Paulo: Paz e Terra, 2004, p. 271 - 364.FL

TEIXEIRA, Palmira Petratti. A ferrovia "The São Paulo Railway" (SPR) e a industrialização da cidade de São Paulo. In. Anuario del CEH, n 2-3, Ano 2 y 3, 2002-2003 
TEIXEIRA, Palmira Petratti. Trilhos e Sonhos: O desenho do interior paulista. In. CADEIRA, João Ricardo de; ODALIA, Nilo (org.). História do Estado de São Paulo: A formação da unidade paulista. São Paulo: Ed. UNESP; Arquivo Publico do Estado de São Paulo; Imprensa Oficial, 2010. p. 235 - 255. 